\title{
PLATAFORMA CINEASTERNA: O SERVIÇO DE STREAMING EM BIBLIOTECAS PÚBLICAS DA SUÉCIA
}

\section{CINEASTERNA PLATFORM: STREAMING SERVICE IN SWEDISH PUBLIC LIBRARIES}

Admeire da Silva Santos Sundströma

\begin{abstract}
RESUMO
Apresenta a Plataforma Cineasterna, que é utilizada como serviço de streaming nas bibliotecas públicas da Suécia, também aborda a origem das bibliotecas públicas na Suécia e como esta vem se relacionando ao longo do tempo, principalmente na atualidade, com o empréstimo de materiais audiovisuais e foca no serviço streaming. Metodologia: Para atingir os objetivos, utilizou-se o método de pesquisa bibliográfica por meio de uma revisão sistemática da literatura, pesquisa de campo a duas bibliotecas públicas suecas, e descrição da usabilidade da plataforma Cineasterna. Resultados: Como resultado, compreendeu-se que a lei de depósito legal para os audiovisuais foi uma decisão de grande importância para compreensão destes enquanto documentos pertencentes a biblioteca no país em questão. Aponta-se também o limite linguístico da plataforma. Além disso, a modalidade de empréstimo por streaming traz novas discussões para área da Ciência da Informação, tais como direitos autorais, plataformas digitais e necessidade de constante inovações nos serviços e produtos das unidades de informação.
\end{abstract}

Descritores: Audiovisual. Serviço de streaming. Cineasterna. Biblioteca pública.

\section{INTRODUÇÃO}

O surgimento das bibliotecas públicas na Suécia está atrelado à implementação do ensino obrigatório e às lutas dos movimentos sociais, conquistas que refletem na atualidade o desenvolvimento cultural do país, visível dentro das unidades de informação e demais centros culturais. Além de bem estruturadas, as bibliotecas contam com um acervo bem diversificado e inúmeras atividades para atender aos seus usuários. Diante da diversidade de material

\footnotetext{
a Doutora em Ciência da Informação pela Universidade Estadual Paulista Júlio de Mesquita Filho (UNESP), Brasil (2021). Professora adjunta da Linnaeus University, Suécia. E-mail: admeire@hotmail.com
}

Inf. Prof., Londrina, v. 10, n. 3, p. 204 - 221, set./dez. 2021. http://www.uel.br/revistas/infoprof/ 
esta pesquisa voltou a atenção para os documentos audiovisuais, mais especificamente, para o empréstimo do acervo fílmico.

A presença desse tipo de documento pode trazer para uma biblioteca, ou outro tipo de unidade informacional, dúvidas relacionadas ao tratamento temático do acervo, conservação, entre outros elementos que já vem sendo trabalhados na literatura brasileira. No entanto, o ponto questionado neste artigo é: como ocorre o empréstimo e a participação do usuário na informação audiovisual disponíveis nas bibliotecas públicas Malmö stadsbibliotek e Lunds stadsbibliotek? Convém ressaltar que este artigo faz parte de um projeto de doutorado intitulado Garantia e hospitalidade cultural no tratamento temático de acervos de animação, financiado pela Coordenação de aperfeiçoamento de pessoal de nível superior - CAPES. Portanto, o presente artigo consiste na publicação dos resultados parciais obtidos durante o período sanduiche e coleta de dados durante agosto de 2019 a agosto de 2020, na Suécia.

Para responder ao questionamento central o artigo se estruturou da seguinte forma: a primeira reflexão trazida corresponde ao relato da origem das bibliotecas suecas, que foi fundamenta por lutas sociais e busca por ações culturais que auxiliassem no combate ao alcoolismo. O segundo ponto debatido é como o audiovisual se tornou um documento também presente nas bibliotecas suecas. Após a introdução desses elementos, o artigo descreve o processo de empréstimo por meio de streaming nas bibliotecas públicas: Malmö stadsbibliotek e Lunds stadsbibliotek, e detalha o serviço streaming do ponto de vista do usuário e do profissional da informação.

A metodologia desta pesquisa corresponde a um estudo de caso e análise de conteúdo, dessa forma, se divide em três etapas: a primeira é bibliográfica, elaborada por meio de busca dentro do repositório da Lund Unuversity com o uso dos seguintes temos: folkebibliotek (biblioteca pública), public library, history of swedish library, audiovisual e film archive. Após a discussão teórica, a segunda etapa foi visita a campo na Malmö stadsbibliotek e Lunds stadsbibliotek, as visitas ocorreram na condição de pesquisadora e na condição de usuário. Durante as visitas foram feitas anotações das conversas com os profissionais que atuavam no setor de referência, registros fotográficos 
e uso dos serviços oferecidos pelas bibliotecas.

A terceira etapa consiste na análise de conteúdo do site, que se deu por meio da avaliação da usabilidade da Plataforma Cineasterna. A leitura que respaldou os caminhos para análise da usabilidade da plataforma ocorreu por meio de Winckler e Pimenta (2002). Para acessar a plataforma é necessário o registro em uma das bibliotecas, nesta pesquisa ela ocorre por meio da Malmö stadsbibliotek. Além disso, a coleta das informações disponíveis no site da Cineasterna será apresentada do ponto de vista do usuário e do bibliotecário.

Como resultado, destaca-se três pontos importantes. A primeira permeia a revisão literária, que trouxe uma dimensão da importância social das bibliotecas públicas para a sociedade e o papel destas no auxílio em tratamentos de vícios. No que se refere ao audiovisual, compreendeu-se que a implementação do depósito legal pela Biblioteca Nacional da Suécia foi um fator também de importância para a compreensão do audiovisual enquanto documento nas unidades de informação.

O segundo ponto importante refere-se aos casos estudados, e ao olhar para o audiovisual dentro das bibliotecas em questão percebeu-se a possibilidade de empréstimo por meio de streaming, essa opção insere a biblioteca em mecanismos atuais de veiculação de filmes e mostra que as bibliotecas podem se adaptar as necessidades e inovações em serviços e produtos atuais.

O terceiro ponto se refere a usabilidade do site, dentre as inúmeras discussões, esta pesquisa aponta que o serviço tem ponto positivo e ponto que pode evidenciar limitações da plataforma. Como ponto positivo destaca-se a interface do site, a diversidade do catálogo e a facilidade de registro nas bibliotecas públicas para o uso do sistema. Como elemento limitante, aponta-se a restrição linguística da Plataforma Cineasterna, pois até o momento de análise do site (agosto de 2020), os únicos idiomas disponíveis para legenda era inglês e os idiomas nórdicos (sueco, finlandês, norueguês e dinamarquês).

\section{A BIBLIOTECA PÚBLICA NA SUÉCIA}

A Suécia é um país escandinavo com uma população de pouco mais de 
10 milhões de habitantes. O país apresenta um PIB 538 bilhões e investe parte do seu orçamento em educação e cultura. No caso das bibliotecas, a Suécia investe cerca de seis bilhões anualmente'. A legislação de 1997 que estabelece como lei o investimento em bibliotecas foi também importante para a existência e garantia dessas instituições (THOMAS, 2010).

Ao refletir sobre o contexto histórico, percebe-se que o surgimento das bibliotecas públicas está atrelado à introdução do ensino obrigatório em 1841. Nesse período houve um incentivo para o uso de bibliotecas paroquiais, pois saber ler era um requisito necessário para o estudo da Bíblia, assim as bibliotecas paroquiais atendiam donas de casas e agricultores. $\mathrm{O}$ acervo era composto basicamente por livros religiosos, o que com o passar do tempo foi fazendo com a população perdesse o interesse no uso desses espaços. No decorrer desse processo, foi ficando evidente que as bibliotecas paroquiais eram incapazes de suprir a necessidade informacional da população e assim, acompanhado de movimentos sociais que surgiam no final século 19, ficou claro a necessidade de se repensar os espaços para leitura (THOMAS, 2010).

No começo do século 20 surgiram vários movimentos sociais que acreditavam no papel das bibliotecas para a democracia, esses movimentos defendiam que, por meio das bibliotecas, as classes desfavorecidas teriam acesso à educação e à cultura. Esses movimentos foram também responsáveis pela criação do "Nationwide network of study circle libraries" que tinha um papel e uma missão social, pois, além de prepararem a população para a vida política, eles acreditavam que o acesso à educação e à leitura poderiam também ser um grande aliado no combate ao alcoolismo (THOMAS, 2010, p. 114).

Torstensson (1990) afirma que o surgimento das bibliotecas na Suécia é considerado como um ramo da educação, mas também ressalta a importância dos movimentos sociais para isso. $\mathrm{O}$ autor apresenta três movimentos: "Os três movimentos populares importantes historicamente na Suécia são: o movimento de avivamento (igreja livre), o movimento de temperança e o movimento dos trabalhadores." (TORSTENSSON, 1990, p. 14, tradução nossa).

Por meio da leitura de Thomas (2010) e Torstensson (1990), percebeu-se

\footnotetext{
1 Os dados são referentes a pesquisa de Thomas, (2010).
} 
que o surgimento das bibliotecas na Suécia esteve atrelado ao respeito a democracia e a introdução do ensino obrigatório no país. Além dos movimentos sociais mencionados, Valfrid Palmgren também se destaca como alguém que desempenhou um papel significativo para a história das bibliotecas suecas.

De acordo com Wallin (1998), Valfrid Palmgren foi a primeira mulher a se qualificar como bibliotecária para trabalhar em uma biblioteca sueca, isso ocorreu no ano de 1905, momento em que a sociedade ainda era muito conservadora e não permitia que as mulheres trabalhassem sem a permissão dos seus responsáveis. Ainda assim, superando os preconceitos contra mulheres do período, Valfrid Palmgren viajou para os EUA, visitou várias bibliotecas, analisou como as bibliotecas se estruturavam e voltou para a Suécia para compartilhar o conhecimento adquirido, assim pode introduzir na Suécia o sistema americano de biblioteca.

Thomas (2010) afirma que o aumento do uso das bibliotecas ao longo do tempo ao invés do declínio ocorre porque a população da Suécia tem o hábito de ler, agregado a isso, ela aponta outros fatores como, por exemplo, o fato de que as bibliotecas apresentam com uma estrutura e uma rede de distribuição eficiente e totalmente capacitada, o que facilita o uso. A autora também pontua que o longo inverno da Suécia faz com que as pessoas queiram passar mais tempo dentro de casa, lendo. "De acordo com as estatísticas atuais, os 290 sistemas de bibliotecas públicas, anualmente, contavam com 2,6 milhões de usuários, que fizeram 68 milhões de visitas e emprestaram quase 70 milhões de itens. Para uma população de 9 milhões, isso significa cerca de 7,6 empréstimos por habitante." (THOMAS, 2010, p. 113, tradução nossa).

A foto a seguir é referente a Malmö stadsbibliotek. 
Figura 1 - Biblioteca pública de Malmö

Fonte: Dados da pesquisa (2019)

Thomas (2010) também comenta e explica sobre o sistema atual de bibliotecas:

O sistema de bibliotecas sueco é uma rede de bibliotecas bem desenvolvida em todo o país. A rede inclui 290 sistemas de bibliotecas públicas com mais de 2.000 pontos de serviço, cerca de 4.000 bibliotecas escolares, 115 bibliotecas médicas e de pacientes, uma Biblioteca Nacional, 39 bibliotecas universitárias e universitárias e cerca de 40 bibliotecas especiais com cerca de 200 pontos de serviço, 20 bibliotecas municipais, três centros de empréstimo e uma biblioteca de repositório. Há também uma biblioteca especial para livros falados, a Biblioteca Sueca de Livros Falados e Braille. (THOMAS, 2010, p. 111, tradução nossa).

As bibliotecas públicas e universitárias da Suécia apresentam um sistema unificado, Thomas (2010) explica que isso é reflexo de uma mudança histórica, ela parte da evolução do ensino superior no país, pois quanto mais pessoas foram sendo inseridas no ensino superior, maior era o uso das bibliotecas públicas. No entanto, a autora ressalta que, apesar das bibliotecas universitárias também serem abertas à comunidade, estas não apresentam muitos usuários fora da comunidade acadêmica, a presença da comunidade é notada com mais evidências nos empréstimos entre bibliotecas. A cooperação entre bibliotecas é garantida por lei, as bibliotecas universitárias devem dar suporte tanto para as 
bibliotecas públicas, como para as bibliotecas escolares (THOMAS, 2010).

Cabe pontuar que o perfil de usuários vem mudando, e, ao analisar os dados estatísticos, a autora conclui que os usuários estão migrando para o ambiente digital, não totalmente, mas uma quantidade significativa. Essa mudança tem sido notada com maior evidência nas bibliotecas universitárias (THOMAS, 2010).

As bibliotecas da Suécia contam com um sistema de pesquisa em base de dados unificado. O sistema é composto por bibliotecas universitárias, centro de pesquisa e apenas 20 bibliotecas públicas. Para Thomas (2010) a função da base de dados vai além de dar acesso ao material que está disposto na Libris, para a autora: "A ideia por trás do sistema de biblioteca do condado era criar uma infraestrutura nacional para garantir que todos os cidadãos tivessem igual acesso ao conhecimento e à cultura." (THOMAS, 2010, p. 116, tradução nossa).

Dessa forma, a ideia de sistema unificado nas bibliotecas no país, de acordo com Thomas, está atrelada novamente a busca por formas democráticas de acesso à cultura e conhecimento. Além da Libris, existem também outras formas de cooperação entre as bibliotecas de diferentes segmentos.

A infraestrutura base das redes de bibliotecas provém das bibliotecas municipais, que são extremamente importantes para a rede nacional de bibliotecas, mesmo que o sistema apresente pontos que ainda podem ser melhorados, Thomas (2010) afirma que as bibliotecas são encorajadas a cooperarem, convém destacar o seguinte trecho:

As bibliotecas municipais incentivam a cooperação e o desenvolvimento por meio de projetos de desenvolvimento regional e inter-regional, como desenvolvimento de TIC, treinamento profissional, promoção da leitura, desenvolvimento de serviço de biblioteca para diferentes grupos-alvo, aprendizagem ao longo da vida, etc. (THOMAS, 2010, p. 116, tradução nossa).

O catálogo unificado foi automatizado em 1972, ano de lançamento de Library Information System (LIBRIS), mantido pela Biblioteca Nacional da Suécia. Por meio do catálogo é possível ter acesso à informação sobre o material pesquisado e em qual biblioteca o material pode ser encontrado. Atualmente, "LIBRIS contém mais de 6 milhões de títulos de mais de 300 bibliotecas. Após uma decisão do governo, o LIBRIS foi disponibilizado gratuitamente online ao 
público em 1997. O número de pesquisas ultrapassa 12 milhões em uma base anual". (THOMAS, 2010, p. 117, tradução nossa).

A relevância internacional do catálogo fez com que a Suécia repensasse sua forma de classificação, pois no país era utilizado o Swedish classification scheme SAB (Esquema de Classificação Sueco), um esquema nacional de classificação. A mudança para Dewey visou facilitar o compartilhamento de dados em âmbito internacional, sem a necessidade de alteração na classificação (THOMAS, 2010, p. 118). No entanto, algumas bibliotecas ainda utilizam o Swedish classification scheme $S A B$, especialmente as bibliotecas públicas.

A biblioteca nacional da Suécia é responsável pelo depósito legal preservando e viabilizando todo o material produzido no país para a população. Thomas (2010) afirma que após a publicação dos materiais, eles são inseridos e disponibilizados quase que imediatamente na LIBRIS para acesso das demais bibliotecas. (THOMAS, 2010, p. 121).

\subsection{Audiovisual nas Bibliotecas Suecas}

A Biblioteca Nacional da Suécia faz o trabalho de depósito legal aos materiais bibliográficos. Da mesma forma, o direito de garantir a preservação foi aplicado aos documentos audiovisuais levando à determinação, no ano de 1979, que a National Archive of Recorded Sound and Moving Images (Swedish Statens ljud- och bildarkiv, SLBA), e inicialmente chamada de Arkivet för ljud och bild (ALB), seria responsável pela salvaguarda de todo o material audiovisual produzido no país. Os materiais que seriam abarcados na preservação seriam:

- todos os programas transmitidos pela Swedish Broadcasting Corporation. Isso incluirá programas de rádio e televisão nacionais e regionais - todos os programas de TV via satélite transmitidos da Suécia - todos os filmes, suecos e estrangeiros, exibidos nos cinemas suecos - todos os discos de gramofone e fitas de som produzidos na Suécia - todos os videocassetes vendidos ou alugados em Suécia (ALLERSTRAND, 1992, p. 228, tradução).

Allerstrand (1992) ainda destaca que os novos formatos surgidos com a evolução tecnológica são incorporados ao acervo por meio da revisão da legislação do depósito legal. E sobre a característica do órgão de preservação o 
autor afirma que é algo entre um arquivo e uma biblioteca e que, inicialmente, a instituição era administrativamente desligada da biblioteca e o acervo não fazia parte do catálogo coletivo.

O SLBA também era responsável pelo controle de acesso ao acervo, pois os direitos autorais dos materiais eram protegidos pela lei de Copyright restrictions. Isso fez com fosse que atribuída ao SLBA a função de controlar a distribuição de cópias, sendo esta só permitida para fins acadêmicos. Outra possibilidade foi a parceria estabelecida com a Association of Swedish Film Producers, que enviava para as produtoras os pedidos de cópias, assim elas analisavam os pedidos de entrega de cópias do material para outras instituições (ALLERSTRAND, 1992).

A SLBA se interligava a outras instituições para administrar o acesso ao material sendo a responsável pelo empréstimo a bibliotecas universitárias, centros de pesquisas e bibliotecas públicas. As produtoras se mostraram contrárias a essa proposta porque, para elas, o acesso a esse material não deveria ser viabilizado em bibliotecas, apenas em casos de estudantes de cinema, pois acreditavam que o acesso deveria ser restrito aos profissionais (ALLERSTRAND, 1992).

Durante esse período, o autor apresenta também a preocupação em torno do controle de empréstimo e a dificuldade da recuperação precisa da informação. Convém observar o trecho a seguir:

Muitas vezes é difícil encontrar exatamente o item desejado em uma fita. Por exemplo, se nenhuma marca de tempo for inserida, pode ser muito demorado pesquisar uma declaração específica ou uma entrevista em uma fita de rádio - que pode conter 24 horas de duração. As atividades de empréstimo em um arquivo audiovisual são, portanto, muito mais lentas e trabalhosas do que em uma biblioteca baseada em texto (ALLERSTRAND, 1992, p. 230).

A fala do autor demonstra uma preocupação recorrente em acervos de documentos audiovisuais, seja ele brasileiro ou sueco, que é a questão da organização e acesso à informação disponível nesse tipo de documento.

Allerstrand (1992) resume essa problemática como mais devagar e trabalhosa que os materiais escritos.

No ano de 2009, o acervo da National Archive of Recorded Sound and 
Moving Images for Audiovisual Material passou a integrar a Biblioteca Nacional da Suécia,

Além das coleções impressas, o Departamento de Mídia Audiovisual contém mais de 7 milhões de horas de material gravado. O Arquivo Nacional Sueco de Som Gravado e Imagens em Movimento garante, desde 1979, que a mídia de áudio e filme seja gravada e armazenada. As coleções audiovisuais são compostas principalmente por gravações de rádio, televisão, cinema, música de vídeo e gravações multimídia. (THOMAS, 2010, p. 122, tradução nossa).

A autora ainda pontua que o fato de muitos materiais serem produzidos apenas em meio eletrônico foi preciso se pensar em uma legislação para o depósito legal (THOMAS, 2010, p. 120). A preocupação com a nova legislação sobre o depósito legal de material inteiramente eletrônico também é destacada por Allestrand (1992).

Há também o Svensk mediedatabas (SMDB) que é um serviço da Royal Library e oferece o conteúdo produzido na Suécia desde 1979. Conta com programas de televisão, rádio, filmes e muitos outros. O site também apresenta dicas de como efetuar pesquisas no site. Além de sugerir pesquisas por título, nome e data, o site também indica as possibilidades de combinações e uso de operadores boleanos.

Percebe-se a tendência de crescimento na participação do usuário no momento de organização. Quando se fala da viabilidade desse material, também são levantadas questões em torno dos direitos autorais e copyright. Devido às inúmeras nuances do audiovisual, está pesquisa se centrou na análise e apresentação da Plataforma Cineasterna.

\section{RESULTADOS E DISCUSSÕES}

A metodologia adotada nesta pesquisa é composta por três etapas: pesquisa bibliográfica, visita a campo e descrição da usabilidade do site. A pesquisa bibliográfica se baseou em textos disponíveis nas bibliotecas da Universidade de Lund e em suas respectivas bases de dados. Por meio dessa pesquisa, obteve-se a base teórica a respeito do surgimento das bibliotecas no país e outras temáticas debatidas acima, na parte 2 . 
Após o levantamento bibliográfico, sistematização dos dados e redação da parte teórica, o passo seguinte foi estabelecer os parâmetros que seriam utilizados para observar as bibliotecas e o que deveria ser questionado aos funcionários. As questões eram: quais são as opções de acervo audiovisual disponíveis na biblioteca? A biblioteca conta com equipamentos para o acesso à informação audiovisual dos diversos tipos de formato disponíveis na biblioteca? Como devo proceder para emprestar esses materiais? E assim por diante. As questões eram abertas e o entrevistado tinha a liberdade de falar abertamente sobre os serviços da biblioteca. Os entrevistados eram informados de que as informações coletadas seriam utilizadas como dados de pesquisa.

Como resultado da conversa aberta, destaca-se a doação do livro feita por um dos funcionários para o enriquecimento da pesquisa, a saber: "Projetando um espaço igual: Métodos, escolhas e lições aprendidas" (Att gestalta ett jämställt rum: Metoder, vägval och lärdomar). No entanto, a análise desse material poderá ser feita em outro momento, pois o foco do livro não é audiovisual.

A descrição da usabilidade da Plataforma Cineasterna foi o último passo desta pesquisa porque o conhecimento da Plataforma só ocorreu após as visitas às instituições de Malmö stadsbibliotek e Lunds stadsbibliotek e após diálogos com os gestores. Ressalta-se que o uso da plataforma ocorreu por meio dos serviços oferecidos pela Malmö stadsbibliotek.

Sendo assim, para apresentar avaliação de usabilidade do serviço de streaming, esta pesquisa abordou duas perspectivas durante a análise das informações da página. A primeira é do ponto de vista do bibliotecário e a segunda é do ponto de vista do usuário, ambas com o método de inspeção, isto é, quando o pesquisador navega na página observando os elementos do ponto de vista de quem está utilizando (WINCKLER; PIMENTA, 2002).

Do ponto de vista do profissional bibliotecário os parâmetros são: especificações técnicas e estrutura da página. No que refere ao usuário, priorizou-se a descrição da interface, estrutura e aparência geral. Descartou-se a comparação com qualquer outro serviço de streaming, pois a biblioteca não objetiva o lucro com a oferta do serviço. Diante disso, convém apresentar a 
descrição da usabilidade do site.

O primeiro ponto a ser destacado é que todas as bibliotecas da rede pública da Suécia contam com a possibilidade de oferta desse serviço de streaming aos usuários. $O$ valor que a biblioteca paga é de acordo com a quantidade de empréstimos efetuados pelos usuários. Assim, fica a critério da biblioteca a quantidade de filmes emprestados e o período de uso para cada filme por parte dos usuários. Todas essas informações devem ser passadas ao Cineasterna como modo de estabelecer o teto de gastos, mas tais critérios podem ser facilmente alterados diretamente no sistema por meio do bibliotecário responsável pela administração do mesmo.

A biblioteca que contrata o serviço não precisa prover de nenhuma especificação técnica a mais para oferecer o serviço aos usuários. Mas, no ato da contratação, deve indicar os nomes que terão acesso à página como administradores sendo estes responsáveis pela consulta aos dados estatísticos que podem apontar os títulos mais emprestados e entre outros dados relevantes. E, ao contratar o serviço, a biblioteca recebe o pacote de marketing para a divulgação do serviço em sua comunidade (CINEASTERNA, 2020)

No site do próprio Cineasterna informa a data de lançamento do serviço nas bibliotecas públicas da Suécia, que foi em abril de 2017, na Biblioteca de Vaggeryd. De acordo com o site, o serviço foi muito bem recebido pelos usuários e funcionários da biblioteca em questão. Até o momento, o Cineasterna atende cerca de 160 municípios do país, o que corresponde a mais de 1,8 milhões de usuários.

As produções disponibilizadas na plataforma não têm limitações geográficas, isso quer dizer que filmes de vários países podem ser encontrados disponíveis na plataforma. Após a contratação, o serviço pode ser disponibilizado em poucos dias para os usuários da instituição.

A seguir, encontra-se uma imagem da página inicial da plataforma, convém ressaltar que a página está em português porque foi utilizada a tradução automática do Google para tal. 
Figura 2 - Site do serviço de streaming

Fonte: https://malmo.se/Uppleva-och-gora/Biblioteken/Biblioteket-hemifran/Film.html (2020)

O site informa que são mais de 2500 títulos de filmes disponíveis para empréstimo e a atualização do catálogo ocorre semanalmente. Para acessar os filmes é necessário apenas ser cadastrado na biblioteca e acesso à internet no local em que deseja acessar o filme escolhido, seja smartphone, computador ou smart tv. O cadastro da biblioteca pode ser feito de forma gratuita na própria biblioteca, mediante a apresentação de um documento de identificação².

Para acessar o filme desejado é preciso acessar 0 site www.cineasterna.se, selecionar a biblioteca na qual você tem o cadastro, escolher o filme desejado, digitar o código do cadastro na biblioteca e "emprestar". Assim, você tem acesso ao filme escolhido por até 48 horas, cada usuário pode "emprestar" (ou acessar) até dois filmes por semana. Os filmes não podem ser baixados, mas podem ser reproduzidos quantas vezes for necessário

${ }^{2}$ A autora desta pesquisa fez o cadastro na biblioteca apenas mediante a apresentação do passaporte, o cartão da biblioteca foi dado instantemente, logo em seguida já foi possível o empréstimo de materiais disponibilizados pela biblioteca e ter acesso à base de dados e demais serviços da instituição, o que incluía a Plataforma Cineasterna. 
durante as 48 horas em que o acesso ao filme estiver liberado. Não é necessário o uso de aplicativo especial, qualquer navegador da internet pode dar acesso ao conteúdo.

Outra regra importante também é a faixa etária, pois a plataforma bloqueia o acesso aos filmes dos quais o usuário não tem a idade indicada para assistir, o bloqueio se baseia nas informações apresentadas no ato do cadastro na biblioteca. Os filmes são exibidos em alta definição e as opções de legendas abrangem o inglês e os idiomas nórdicos (sueco, finlandês, norueguês e dinamarquês)

Figura 3 - Página do Cineasterna

Fonte: https://www.cineasterna.com/en/ (2020)

Não é necessário fazer o download de plug-in ou aplicativos. Apenas ter conexão com a internet. Apesar do catálogo ser unificado, as bibliotecas são livres para selecionarem seus próprios títulos e criar um acervo próprio de filmes, pois a empresa responsável pela seleção e fornecimento dos filmes para a biblioteca é a FörlagEtt. Ao estar logado no sistema, o usuário tem acesso à lista de filmes que já emprestou e, caso queira, pode continuar vendo um filme no momento exato que parou anteriormente porque o sistema conta com essa possibilidade. Além disso, convém pontuar que o uso dos filmes é de caráter privado, sendo assim o usuário não pode exibir o filme de modo público. 


\section{CONSIDERAÇÕES}

Os serviços de streamings estão cada vez mais presentes no dia a dia das pessoas que gostam de filmes, no entanto, há um valor a ser pago por esse tipo de serviço e nem sempre todas as pessoas podem arcar com tais despesas. Além disso, o acesso ao filme pode ser considerado também acesso à cultura. Para finalizar o presente estudo, convém retomar aos dois objetivos: O primeiro, apresentar a origem das bibliotecas públicas na Suécia. Foi importante retomar, mesmo que de modo sucinto, a história das bibliotecas, pois a busca por novos meios de empréstimos de filmes mais democráticos está intimamente ligada à história das bibliotecas suecas, que estão constantemente buscando meios de democratizar o acesso a qualquer tipo de documento, sejam filmes, livros e/ou outros documentos.

Desta forma, nota-se que o segundo objetivo se qualifica como um elemento dentro da missão das bibliotecas públicas suecas, sendo este: apresentar como a biblioteca pública vem se relacionando ao longo do tempo, principalmente na atualidade, com o empréstimo de materiais audiovisuais, cujo foco foi a plataforma de streaming Cineasterna.

A experiência com a plataforma Cineasterna mostrou que ela apresenta uma interface fácil e simples, seja para os usuários como para os funcionários da biblioteca. Os únicos pontos negativos é que, caso o usuário não acesse o site da biblioteca, ele terá dificuldades de saber da existência desse serviço. Além disso, a restrição aos idiomas nórdicos como opções de legenda também limita o uso da plataforma.

O primeiro ponto negativo foi contatado durante as visitas nas bibliotecas, pois assim foi possível encontrar diversos filmes em formato DVD, no entanto, não havia nenhum cartaz informando a existência do serviço.

O segundo ponto negativo destacado é entendido como tal, pois as cidades de Malmö e Lund, por exemplo, por serem cidades universitárias e com grande número de pessoas de outros países contam com pessoas que falam outros idiomas além das línguas nórdicas. E a Plataforma Cineasterna, até o momento da escrita deste relato, não disponibilizava outras opções de idioma. 
Cabe ressaltar que o governo sueco fornece de modo gratuito o ensino da língua sueca para a todas as pessoas que recebem o visto permanente, familiar e/ou de estudo. Mas o cadastro e acesso aos documentos das bibliotecas podem ser feito por qualquer pessoa, mesmo aquelas que só estão de visitando o país.

Como ponto positivo da Plataforma, destaca-se a interface quase intuitiva, as explicações sobre como usar o sistema, a diversidade de material e a atualização constante do catálogo. Ao término dessa experiência percebeu-se que a Cineasterna amplia as possiblidades de empréstimo dentro de uma biblioteca e reforça a importância de estudos em torno de materiais audiovisuais na Ciência da Informação. E propõe também futuras reflexões a respeito de como as inovações dentro das bibliotecas e outras unidades de informação estão se moldando com base em produtos existentes no mercado.

\section{REFERÊNCIAS}

ALLERSTRAND, Sven. The interleading of audiovisual materials in Sweden. IFLA journal, 1992, p. 228-231.

PLATAFORMA CINEASTENA. Disponível em:

https://docs.cineasterna.com/bibliotekssystem. Acesso em: 26 de ago. 2020.

FOLK BIBLIOTEK LUND. History of the the City Library: Join us on a journey through time from the first library on Krafts Torg to Sankt Petri Kyrkogata. Disponível em:

https://biblioteksportalen.lund.se/en/web/arena/stadsbibliotekets-historia.

Acesso em: 06 dez. 2019.

LÅNA STRÖMMANDE FILM. Malmo Stad. Disponível em:

https://malmo.se/Uppleva-och-gora/Biblioteken/Biblioteket-hemifran/Film.html.

Acesso em: 16 dez. 2019.

MOVING PICTURES AND SOUND. Digital Preservation Handbook. Disponível em: https://www.dpconline.org/handbook/content-specific-preservation/movingpictures-and-sound. Acesso em:14 nov. 2019. Não foi localizada a citação no texto

SMIT, Johanna Wilhelmina. O documento audiovisual ou a proximidade entre as 3 marias. Revista Brasileira de Biblioteconomia e Documentação, São Paulo, v. 26, n. 1-2, p. 81-85, 1993. Disponível em:

http://rbbd.febab.org.br/rbbd/article/view/396/370. Acesso em: 13 nov. 2019.

Não foi localizada no texto 
SVENSK mediedatabas. Disponível em: https://smdb.kb.se/smdb/soktips/. Acesso em: 12 ago. 2020.

TORSTENSSON, M. Library History Research in Sweden: A Field in Development. Libraries \& Culture: A Journal of Library History, n. 25, p. 1126, 1990.

THOMAS, Barbro. Swedish libraries: an overview. IFLA journal, 2010, p. 111130.

WALLIN, Kerstin E. Valfrid Palmgren - kvinnlig visionär på KB. Ingår i Burius, Anders. Några hyll(nings)centimeter: festskrift till Folke Sandgren den 15 februari 1998. Stockholm: Kungliga biblioteket, 1998. (Acta Bibliothecae regiae Stockholmiensis, 58). p. 325-332.

WINCKLER, Marco; PIMENTA, Marcelo Soares. Avaliação de usabilidade de sites web. In: ESCOLA DE INFORMÁTICA DA SBC SUL (ERI), 10., 2002.

Anais [...] Caxias do Sul: Sociedade Brasileira de Computação (SBC), 2002. v. 1, p. 85-137.

\title{
CINEASTERNA PLATFORM: STREAMING SERVICE IN SWEDISH PUBLIC LIBRARIES
}

\begin{abstract}
This article will present the Cineasterna platform, which is a streaming service in Swedish public libraries. In this sense, it will approach the origin of public libraries in Sweden and how it has been related over time with the loan of audiovisual materials and focuses on the streaming service. To reach the objectives, it was used a systematic review of the literature, after a research field in two libraries, and then a usability description of the Cineasterna platform. As a result, It was understood that the law of legal deposit for audiovisuals was a decision of great importance for understanding these as documents belonging to the library in that country. In addition, the streaming service modality brings new discussions to the Information Science area, such as copyrights, collaborative cataloging, and innovations as a requirement of services and products at information centers.
\end{abstract}

Descriptors: Audiovisual. Cineasterna. Video Streaming. Public library.

\section{PLATAFORMA CINEASTERNA: EL SERVICIO DE STREAMING EN LAS BIBLIOTECAS PÚBLICAS DE SUECIA.}

\section{RESUMEN}

Presenta la Plataforma Cineasterna, que se utiliza como servicio de streaming en las bibliotecas públicas de Suecia, también aborda el origen de las bibliotecas públicas en Suecia y cómo se ha relacionado a lo largo del tiempo, especialmente en la actualidad, 
con el préstamo de materiales audiovisuales y se enfoca en el servicio de streaming. Para lograr los objetivos se utilizó el método de investigación bibliográfica mediante una revisión bibliográfica sistemática, investigación de campo en dos bibliotecas públicas suecas y descripción de la usabilidad de la plataforma Cineasterna. En consecuencia, se entendió que la ley de depósito legal de audiovisuales era una decisión de gran importancia para entender estos como documentos pertenecientes a la biblioteca del país en cuestión. También se señala el límite lingüístico de la plataforma. Además, la modalidad de préstamo en streaming trae nuevos debates al área de Ciencias de la Información, como derechos de autor, plataformas digitales y la necesidad de innovación constante en los servicios y productos de las unidades de información.

Descriptores: Audiovisual. Servicio de streaming. Cineastern. Biblioteca Pública.

Recebido em: 15.10 .2021

Aceito em: 27.12.2021 